\title{
A IMAGEM DO PROFESSOR DE LÍNGUA PORTUGUESA - INDÍCIOS DE QUEIXAS
}

\author{
THE IMAGE OF PORTUGUESE LANGUAGE TEACHER - EVIDENCE OF \\ COMPLAINTS
}

\section{LA IMAGEN DEL PROFESOR DE PORTUGUÉS - EVIDENCIA DE QUEJAS}

\begin{abstract}
RESUMO
O presente trabalho é parte integrante do estudo realizado na dissertação de mestrado que analisa registros do licenciando sobre as práticas de ensino. Este tem como finalidade verificar por meio de uma análise discursiva, elementos na escrita que delineiam a imagem do professor supervisor de estágio de língua portuguesa, bem como a imagem de si enquanto professor em formação. O objetivo é verificar nos escritos possíveis indícios de queixas acerca do trabalho do profissional em exercício. As análises são fundamentadas no conceito pêchetiano de formações imaginárias, que designa o que o sujeito pode ou não dizer a partir da posição que ocupa. Os resultados mostram que a imagem do professor supervisor para o professor em formação está muito aquém do esperado. Ele ainda é visto como alguém despreparado, cansado e sem criatividade. O corpus é constituido por excertos de relatórios finais de estágio supervisionado do curso de Letras de duas instituições federais que se encontram disponíveis na base de dados do Grupo de Pesquisa Gepadle (Grupo de estudos e pesquisas em análise do discurso leitura e escrita) que estuda o papel da escrita nas licenciaturas.
\end{abstract}

PALAVRAS-CHAVE: Escrita. Queixas. Professor.

\begin{abstract}
The present work is an integral part of the dissertation that analyzes licensing records about teaching practices. This aims to verify through a discursive analysis, elements in the writing that outline the image of the supervising teacher of Portuguese language training course, as well as the image of herself as a teacher in training. The goal is to check on possible evidence of complaints about the work of professional in-Office. The analyses are based on the concept of imaginary pechetiano that designates what the subject may or may not tell from the position. The results show that the image of the supervising teacher for the teacher in training is far short of the expected. He is still seen as someone unprepared, tired and uninspired. The corpus consists of excerpts from final reports of the supervised internship course in Letters of two federal institutions that are available in the database of the Gepadle research group (Group for studies and research in discourse analysis reading and writing) that studies the role of writing in the undergraduate.
\end{abstract}

KEYWORDS: Writing. Complaint. Teacher.

\section{RESUMEN}

El presente trabajo es parte integral de la tesis doctoral titulada que analiza los registros de licencias sobre las prácticas pedagógicas. Esto tiene como objetivo verificar a través de un análisis discursivo, elementos en la escritura que describen la imagen de un maestro de curso de lengua portuguesa, así como la imagen de sí misma como profesora de en el entrenamiento. El objetivo es comprobar evidencia posible de quejas sobre el trabajo del profesional en ejercicio. El análisis de do se basan en el concepto de imaginario pechetiano que señala lo que el sujeto puede o no puede decir de la posición. Los resultados muestran que la imagen de un maestro para el maestro en formación está lejos de lo esperado. Todavía es visto como alguien sin preparación, cansado y sin inspiración. El corpus consta de extractos de informes finales del curso de prácticas supervisadas en las cartas de dos instituciones federales que están disponibles en la base de datos del grupo de investigación Gepadle (grupo 


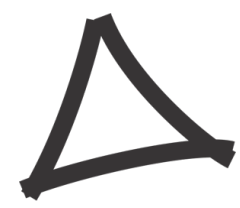

Revista Triângulo

www.seer.uftm.edu.br/revistaeletronica

de estudios e investigación en análisis del discurso de lectura y escritura) estudia el papel de la escritura en la licenciatura.

PALABRAS CLAVES: Escritura. Queja. Maestro.

\section{INTRODUÇÃ̃O}

O professor representa um papel importante na sociedade, por isso é um dos principais focos de discussões relacionadas ao ensino e aprendizagem. A centralidade do professor pode ser encontrada em muitos estudos que discorrem sobre seu papel, seja no processo de formação inicial ou profissional, bem como de seus saberes pedagógicos, da identidade docente, etc.

Para Gatti, Barreto, André (2011, p. 26) o professor é o ator/atriz que está no centro do trabalho educativo institucionalizado, envolvido indissoluvelmente nas relações educativas. Assim, por estar em evidência, o professor é constantemente analisado, o que naturalmente pode resultar em posicionamentos contrários e ou favoráveis ao seu papel. Essa posição de vanguarda permite compará-lo a um soldado que, diante de uma guerra, inevitavelmente fica sujeito a todo o tipo de investida, podendo ou não ser condecorado pela luta.

O professor está sempre susceptível a julgamentos oriundos muitas vezes de pais de alunos, de alunos, de diretores e de seus pares; são discursos que circulam principalmente em textos e âmbitos acadêmicos e nas mídias sociais. É preciso considerar a importância da crítica para o desenvolvimento docente ou de qualquer área. No entanto, o juízo crítico quando é meramente uma repetição de informações se torna improdutivo e pode ser reduzido a um tipo de queixa.

Para Fernández (1994), a queixa em sua fase inicial funciona como o que chama de "lubrificante da máquina inibidora do pensamento", compreende-se um tipo de pensamento estático, "repetível" que não produz transformação, não gera fruto, como exemplifica: "Os governos não se interessam pela educação". Tal construção funciona como um questionamento mascarado o qual denuncia, confirma, mas é aceito como algo imutável, que dá impressão de algo irreversível para o problema da educação. A queixa tal como formula a autora passa por uns estágios e adquire status de juízo crítico quando o pensamento a respeito da realidade provoca mudança tanto interna como externamente (IBIDEM p. 67).

Para ela, a classe das professoras cai na armadilha de pensar que fazem juízo crítico quando, na verdade, fazem apenas reforçar a queixa. Reflete-se a esse respeito quando se avalia nos discursos de relatos de estágio a crítica ao professor apenas para apontar falhas em seu trabalho sem nada acrescentar; quando não há uma contribuição efetiva que otimize o ensinoaprendizagem, como por exemplo, quando se diz:" o professor não sabe o conteúdo". O fato de mencionar que o professor não sabe o conteúdo ministrado não torna fidedigna a afirmação. É preciso apresentar os elementos encontrados na observação/pesquisa que corroboram com a 


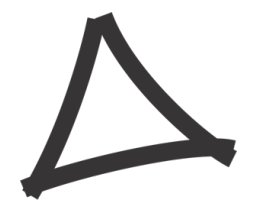

afirmação da existência de algum tipo de fragilidade no ensino, pois não se deve apenas fazer menção categórica sem comprovação.

O discurso do licenciando com o propósito de apontar falhas o coloca numa posição superior à do professor, e quando enuncia, fala a respeito de uma posição da qual ainda não ocupa, com isso, ignora a experiência do supervisor. A inferência é que não realiza um juízo crítico; reclama, queixa-se daquilo que não se conforma, mas não produz transformação. Ocorre que, muitas vezes, se vê inclinado a apontar falhas em determinados aspectos concernentes à escola, mas sem analisar fatores externos, desafios e dificuldades que são enfrentados diariamente pelo professor e nesse sentido, tende a repetir discursos e dogmas estabelecidos por uma determinada doutrina teórica. Nas palavras de Barzotto (2016, p. 39)

\begin{abstract}
O que tem sido visto nos últimos 30 anos é que, na medida em que grupos que sustentam uma proposta para a disciplina de Língua Portuguesa vão ocupando um lugar de poder, aquilo que defendem acaba por se transformar em modismos, por criar tabus, e atrair adesões pouco críticas. (BARZOTO, 2016 p. 39)
\end{abstract}

A compreensão é que os “conhecimentos" produzidos sobre o ensino de língua portuguesa desfavoráveis ao professor, certamente servirão de modelos para reprodução desse tipo de discurso. A pretensão não é de advogar na causa do professor sem um critério, mas entender porque o estagiário se posiciona dessa maneira, pois a inferência é que tal posicionamento contribui para que a queixa se propague, sem produzir algum tipo de transformação. Diante disso, busca-se analisar nos fragmentos dos relatórios possíveis indícios de queixas à atuação do professor.

\title{
2. REFERENCIAL TEÓRICO
}

Para Pêcheux (1969-2014) o discurso é sempre pronunciado a partir das condições de Produção. Esse autor usa como exemplo a representação de um político partidário de um governo de oposição que, por representar os interesses de seu grupo, dado o lugar que está fica submetido a uma relação de forças com o grupo cuja ideologia é oposta, ele afirma: “A mesma declaração pode ser uma arma temível ou uma comédia ridícula segundo a posição do orador e do que ele representa em relação ao que diz, um discurso pode ser um ato político direto ou gesto vazio para dar o troco" (IBIDEM, p. 76). O que corrobora com a afirmação de que não se pode dizer tudo em todo lugar. 


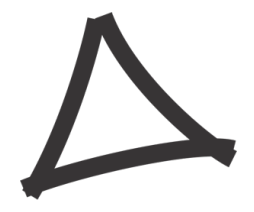

Orlandi (2007) explica que as condições de produção estão relacionadas aos sujeitos e a situação. Elas são compreendidas em sentido estrito (contexto imediato) e em sentido amplo, que diz respeito ao contexto sociohistórico e ideológico. Neste, determinados aspectos da sociedade são levados em conta na construção do sentido. Possenti (2004) ilustra essa distinção apresentada por Orlandi da seguinte maneira:

O que confere ou garante o sentido ao que um enunciador diz não é o contexto imediato em que está situado e ao qual se ligariam certos elementos da língua (ou certas características do enunciado (implícitos), mas as posições ideológicas a que está submetido e as relações entre o que diz e o que foi dito da mesma posição (POSSENTI, 2004, p. 369).

É importante observar nessa perspectiva a necessidade de analisar o sujeito enquanto produtor de um discurso que foi se constituindo ao longo do tempo e não o que foi proferido numa situação específica. Por exemplo, em um diálogo quando os indivíduos apresentam opiniões divergentes acerca de uma determinada visão de mundo, quer seja de cunho político, religioso ou outros, o que está em jogo não é o que foi dito naquele instante, mas a condição de sua produção. Seria preciso olhar para o sujeito para sua formação, seus valores e crenças para perceber a força, a natureza do que foi dito, que por sua vez determina o efeito de sentido. Isso resultará numa espécie de conflito com aquele cuja visão é contrária.

Para Cardoso (2003) as condições de produção devem ser entendidas como representação no imaginário sociohistórico e os interlocutores como representação de lugares determinados na estrutura social; as relações são representadas no discurso pelas formações imaginárias que designam o lugar que destinador e destinatário atribuem a si mesmo e aos outros. O emissor pode antecipar as representações do receptor e em função dessa imagem formular o discurso. Essas antecipações são formuladas com perguntas (implícitas) do tipo: Quem sou eu para lhe falar assim? Quem é você para que eu the fale assim? O que é isso de que vou lhe falar? As fórmulas correspondem a: [IA(A)] - Imagem que o sujeito em A (o enunciador) tem do sujeito em A; formação [IA(B)] - A imagem que o sujeito em A tem do sujeito em B; o enunciatário a formulação [IA(R)] a qual se dirige 


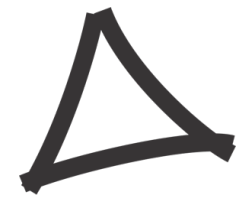

Revista Triângulo

www.seer.uftm.edu.br/revistaeletronica

ao referente (IBIDEM, p. 82). Há, contudo, outras formulações. O exemplo utilizado por Possenti (2004) reforça essa ideia:

se um diretor de prisão se dirige a presos, o diretor e os presos não devem ser concebido como se tratasse de uma certa pessoa (bonachona ou dura) diante de certas outras pessoas (injustiçadas ou tensas), envolvidas em uma relação de interlocução, mas como posições historicamente constituídas em sociedade em que essas funções se circunscrevem à certas regras (POSSENTI, 2004, p.368)

Diante disso, depreende-se que um discurso de ordem produzido pelo diretor é resultado da condição de sua produção. A posição ocupada determina o dizer (a formação discursiva) como ocorre na escola entre o professor/ aluno, o supervisor de estágio e o licenciando, cujas posições indicam o que pode ser dito. Por exemplo, um aluno não pode determinar as ações que o professor deve realizar na aula, entretanto, pode o professor determinar as ações de seu aluno. Assim, a posição de domínio de um em sobre o outro determina as relações de forças entre os sujeitos do discurso.

Essa teoria é imprescindível para ajudar a perceber no discurso do licenciando, no jogo de imagens, na relação professor/ licenciando, possíveis embates ideológicos considerando as condições de sua produção. O sujeito em A será representado pelo licenciando, professor em formação a fim de perceber qual a imagem tem de si mesmo - a formação [IA(B)]. A imagem que o sujeito em A tem do sujeito em B (o enunciatário), neste caso, é a imagem que o professor em formação tem em relação ao professor em atividade considerando o lugar e a posição de aluno.

\section{MATERIAIS E MÉTODOS}

Os excertos analisados correspondem a uma parte do corpus da pesquisa que é formado por relatórios finais de estágio supervisionado I e II dos cursos de Letras da UFTM e da UFPA. Neste trabalho são analisados cinco fragmentos designados por RETM (UFTM) e REPA (UFPA), que diz respeito às partes do relatório destinada a atividade de observação ao professor, e regência do estagiário. O método consiste realizar uma análise do discurso 


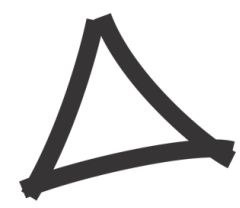

Revista Triângulo

www.seer.uftm.edu.br/revistaeletronica

a partir das condições de produção, na busca por elementos na escrita que possam delinear a imagem do sujeito professor e licenciando.

\section{ANÁLISE DOS DADOS E RESULTADOS}

Os excertos a seguir foram retirados dos tópicos: observação( em que são relatadas as observações ao professor e regência( em que licenciando escreve sobre sua própria prática).

\section{Fragmento 1 RETM 1}

Durante as aulas em que a professora explicava algum conteúdo da língua referente ao livro didático, a maioria dos alunos não demonstrava muito interesse e ela tinha alguns problemas para fazer as turmas focarem na aula. A professora utilizava o livro didático com frequência portanto, isto acontecia com frequência. De modo geral pudemos observar que os alunos dos oitavos anos embora não apresentassem problemas muito graves de compreensão textual, escrita e leitura, salvo algumas exceções, expunham claramente para a professora a opinião de que as aulas de Língua Portuguesa não eram muito atrativas para eles

Um dos aspectos da escrita do trecho acima diz respeito à conduta da professora em sala de aula: as limitações de conteúdo e controle da turma. Há no discurso do licenciando a necessidade de relatar e destacar as fragilidades da docente como é possível observar nos trechos: "Durante as aulas em que a professora explicava algum conteúdo". O termo "algum conteúdo" indica que o licenciando desconsiderou o saber ministrado pela professora porque não se sabe ao certo qual conteúdo estava sendo ensinado. A inferência é que, para o licenciando, esse era um dado irrelevante, uma vez que o foco da análise centrava na docente, não na aula como um todo.

O que salta a vista no discurso é que as aulas não são interessantes, conforme afirmação "atestada" pela "maioria" dos alunos segundo o que diz o licenciando: "A maioria dos alunos não demonstrava muito interesse e ela tinha alguns problemas para fazer as turmas focarem na aula". Nesse enunciado, há uma generalização quando afirma que a maioria era indiferente a aula, sem indicar o que elegeu como problema. Ainda no trecho acima é possível constatar que o foco da observação neste primeiro momento é a docente. A professora é descrita como alguém que não consegue prender a atenção dos alunos, o que a leva o estagiário a atestar que as aulas não são interessantes. 


\section{$\Delta$}

\section{Revista Triângulo}

www.seer.uftm.edu.br/revistaeletronica

No entanto, é preciso entender quais as condições de produção desse discurso, o que a leva a atestar tal afirmação? Essa indagação surge porque nos trechos: "Ela tinha alguns problemas para fazerem as turmas" e "os alunos dos oitavos anos embora não apresentassem problemas", o estagiário revela que acompanhou várias turmas e não somente uma. Então, será que a postura adotada pela professora é a mesma em todas as turmas considerando, pois, a diversidade de alunos?

Ainda sobre o mesmo fragmento, outro aspecto descrito pelo licenciando é o frequente uso do livro didático ${ }^{1}$ pela professora: A professora usava o livro didático com frequência, portanto, isso acontecia com frequência. Nesse enunciado, nota-se que o livro didático, é posto como a principal ferramenta que motiva o desinteresse dos alunos. $\mathrm{O}$ uso do material como recurso na ministração das aulas é tema recorrente nos cursos de formação de professores. $\mathrm{O}$ licenciando enuncia, portanto, um discurso acadêmico.

Para Coracini (2011, p. 18-23) ao realizar uma pesquisa em revistas brasileiras afirma ter encontrado poucos artigos com análises consistentes do livro didático, dos que pesquisou em sua maioria se debruçavam a criticar o material. Pertinente acrescentar uma das declarações da autora: "Não significa que os livros didáticos sejam bons ou ruins: significa apenas que não usar o livro didático não resolve o problema" o que leva a pensar sobre o porquê da recorrência do uso do livro como uma bíblia no ensino. Uma das respostas pode estar relacionada ao fato do professor nem sempre ter autonomia para a escolha de seu material pedagógico e até mesmo pela dificuldade de trabalhar com outros recursos como material impresso e mídias digitais.

Outro aspecto observado no enunciado do RETM1 diz respeito ao aluno que não tem problemas muito graves de compreensão linguística: "De modo geral podemos observar que os alunos dos oitavos anos não apresentavam problemas muito graves de compreensão textual, escrita e leitura". E como isso foi atestado? Que elementos comprovam essa afirmação?

No trecho está implícito que os alunos de fato recebem conhecimento, pois as habilidades, ainda que apresentem fragilidades, são desenvolvidas. Os alunos, diferentemente, são avaliados com outra perspectiva, como se a postura deles e ações em sala corressem dentro

\footnotetext{
${ }^{1}$ Neste relatório, está descrito que a professora apresenta as razões que justificam o uso do livro. Primeiro, há um limite para tiragens de cópias, então não pode fazê-lo para todas as aulas. Segundo, os alunos quando realizam atividades sem o livro tendem a não levá-lo mais para a escola dificultando o trabalho quando a professora precisa utilizá-lo.
} 


\section{$\Delta$}

\section{Revista Triângulo}

www.seer.uftm.edu.br/revistaeletronica

da normalidade. O que se quer dizer é que a avaliação do estagiário acerca dos sujeitos professora e alunos segue critério de um olhar positivo para os alunos e negativo para a professora.

Para essa observação, foi estabelecido um paralelo no discurso onde há algumas pistas de como isso é delineado no RETM1, nos trechos: "Eles não apresentavam muitos problemas (referência aos alunos) Ela tinha alguns problemas (referência à professora)". Esse enunciado segue a mesma estrutura onde se nota que ambos os sujeitos apresentam problemas, embora atenue os do aluno e enfatize o da professora. Importas notar que não se sabe ao certo em que o licenciando se baseia para levantar essa afirmação.

Outros indícios de queixas podem ser encontrados também no enunciado:

\section{Fragmento 2 - RETM 2}

Findando o debate, passei a palavra da professora1, da qual esperava a partir daí, iniciar as discussões sobre os componentes de um texto argumentativo, como sua estrutura e construção. Fui surpreendida, entretanto, pelo seu imediato pedido a turma: Agora produzam uma dissertação de 30 linhas sobre a questão da maioridade penal do Brasil. Fiquei algum tempo me perguntando sobre o que acabara de acontecer imaginando a possibilidade de que ela esperasse de mim a explanação sobre dissertação argumentativa. ... segui para a turma B tendo os mesmos cinquenta minutos, mas com um planejamento completamente diferente convicta de minimizar todas as folhas possíveis....

O trecho em questão apresenta indícios de imagens negativas do professor e positivas do licenciando. Para este, a professora estava ensinando os alunos sobre textos argumentativos. O estagiário propôs um debate sobre o tema: maioridade penal; foi bem aceito, porém, após o debate, revela que esperava uma explanação da professora sobre dissertação argumentativa, o que não ocorreu, levando-a a uma frustração.

A observação apontada parece pertinente ao momento, pois percebeu-se que poderia ter sido mais bem aproveitada a atividade. Pelo descrito no relatório, há comodidade por parte da professora em propor a realização de um texto de 30 linhas como atividade estratégica para silenciar a turma, que parece, na visão do licenciando, ser suficiente para passar o tempo da aula. Nessa cena discursiva, é possível notar, no jogo de imagens, a reclamação e a inversão dos papéis dos sujeitos do discurso.

A reclamação aparece como efeito de sentido produzido no discurso e o destaque recai para as formas verbais: "esperava", "surpreendida", "perguntando" e "Imaginando", que dão 


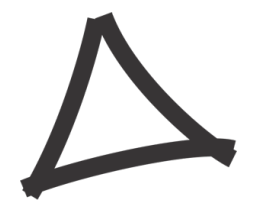

Revista Triângulo

www.seer.uftm.edu.br/revistaeletronica

força argumentativa para o enunciado. A queixa ocorre pelo fato do professor não corresponder à expectativa em relação à continuidade do trabalho iniciado. Os planos foram frustrados, o projeto da aula falhou. Todavia, essa reclamação constituiu-se como resultado de uma reflexão após a aula que provocou mudanças nas ações do aluno que, por conseguinte, reformula o planejamento como medida preventiva de erros. Como não há descrição de nenhum diálogo entre professores envolvidos, como troca de experiências a respeito da ocorrência, não se pode afirmar que a reclamação tenha produzido efeito também no professor supervisor. Esse tipo de reflexão pós queixa talvez seja o início de um processo de juízo crítico, e requer uma transformação no pensamento interno de modo que possa refletir externamente. (Ibidem p. 67).

O modelo de aprendizagem na formação de professores, no tocante a orientação prática, segundo Garcia (2005), se baseia numa aprendizagem por observação em que o professor inexperiente aprende com o experimentado, ou seja, o discípulo aprende com o mestre. No entanto, o enunciado "Findando o debate, passei a palavra da professora1, da qual esperava a partir daí, iniciar as discussões" indica haver uma inversão de papéis. O licenciando parece dar as coordenadas da aula ao professor, que deve seguir a orientação, contudo, ao não fazer o esperado, mas o trivial, falha no processo.

As condições de produção do discurso pode ajudar a compreender essa inversão de papéis, através do jogo de imagens formulado por Michel Pêcheux (1969) que corresponde àquilo que o sujeito pode ou não dizer dependendo da posição que ocupa. Nessa perspectiva, causa estranheza o fato do licenciando, na posição de aprendiz, enunciar como se estivesse no lugar do professor. Notam-se as relações de poder entre o licenciando, que formula uma imagem de si em relação à imagem do professor supervisor. Assim, a imagem que o sujeito em A (licenciando) tem do sujeito em B (professor supervisor de estágio), mesmo ocupando uma posição inferior dada a diferença entre a experiência e formação de ambos, é a de alguém que possui um conhecimento que sobrepuja ao do professor em exercício; isso porque, havendo uma mudança de posição, lograria êxito no ensino-aprendizagem.

A conclusão é que, para o licenciando, embora não esteja explícito, há insegurança do professor em ensinar o conteúdo já que, conforme enunciado, este dispunha de tempo para realização da atividade. No relatório, descreve que os alunos não sabiam como fazer um texto argumentativo e não sabiam como fazer a estruturação de parágrafos o que indica que não 


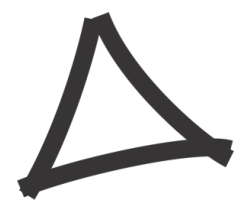

Revista Triângulo

www.seer.uftm.edu.br/revistaeletronica

houve ensino por parte do professor. Desse modo, depreende-se um discurso que traz uma denuncia velada ao trabalho do supervisor de estágio, que se configura como queixa.

Outro sinal de reclamação pode ser observado na sequência, nos dois fragmentos do relatório, REPA1 os quais dizem respeito a uma atividade aplicada pela professora que foi considerada insatisfatória, segundo o enunciado dos licenciandos. A proposta de intervenção, o plano para a regência dos licenciandos foi feito a partir dessa aula:

Fragmento 3 - REPA 1 na observação:

A professora não coordena a formação de duplas na sala, deixando puramente a cargo dos alunos que provocam uma bagunça generalizada com o barulho de carteiras sendo arrastadas. Para que os alunos realizassem a atividade o livro didático foi utilizado para releitura das biografias. Enquanto alguns alunos faziam a atividade outros contribuíam para que o barulho aumentasse, a professora pegava os cadernos para dar o visto em quem havia feito à atividade da aula anterior. A professora assumiu uma atitude apática diante da sala, mesmo com o incômodo que era o barulho em sala, ela não se pronunciava mais para pedir silêncio. Depois de minutos com muito barulho a aula se encerra com a

professora dando visto na atividade realizada.

Fragmento 4 - REPA 1 na intervenção:

Formamos trios de alunos para a realização da atividade, desta vez deixando que os alunos se organizassem. A eles foram entregues uma cópia para cada do texto a ser lido e analisado e uma cópia da primeira atividade que era as questões do contexto de produção e construção composicional. O texto foi lido em voz alta com os alunos acompanhando em leitura silenciosa, enquanto o texto era lido foi possível observar que os alunos estavam concentrados no texto. Essa concentração pode ser devido ao fato que a maioria dos alunos presentes não conhecia nem o livro e nem o filme

Nota-se- que a imagem delineada da professora é a de uma profissional apática conforme o primeiro enunciado: a professora assumiu uma atitude apática. Em outro trecho é caracterizada como desorganizada:

alunos que provocam uma bagunça generalizada com o barulho de carteiras sendo arrastadas; e sem autoridade: deixando a cargo dos alunos, no que diz respeito à tarefa de organização dos grupos diante de uma turma desinteressada com a aprendizagem.

A comparação entre os dois fragmentos leva a observar que existe um conflito. Essa tensão é observada em muitos relatórios entre o embate do discurso do velho e novo método 


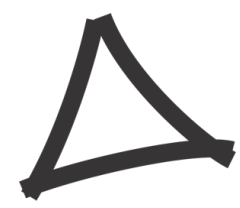

Revista Triângulo

www.seer.uftm.edu.br/revistaeletronica

de ensino. Então, tem-se a imagem que o licenciando tem si e a imagem que o licenciando tem do outro, professor supervisor.

Na posição ocupada pelos estagiários, no trabalho desenvolvido por eles, tudo corre dentro da normalidade, sem muitos problemas. Não há tensão. Um fator muito positivo, já que foi dada autonomia para os alunos se organizarem. Observa-se que houve planejamento para realização desta atividade, uma vez que disponibilizaram cópias para todos os alunos, para que a atividade não fosse retirada do livro didático. $\mathrm{O}$ resultado da aula foi de participação e colaboração por parte dos alunos. Entretanto, chama atenção o fato de não ser apenas um estagiário intervindo, mas três, e com a possível ajuda da professora, somando-se então, quatro pessoas para conduzir a aula, não ficando a cargo de apenas um.

A indagação que surge sobre essa questão é: e se um dos licenciandos estivesse na posição ocupada pela professora, teria êxito como tiveram sendo três? Será que o licenciando sempre disporá de cópias de textos de outras fontes que não as do livro didático? Haja vista que, nas escolas, há uma cota de fotocópias para serem retiradas por cada professor, sem contar que há professores que trabalham com mais de uma turma.

Uma dificuldade que pode ser encontrada para realização da aula na educação básica diz respeito às mídias que não podem ser sempre usadas, tais como o data show porque é um recurso que deve ser compartilhado com todos os professores que atuam na escola; assim, é preciso agendamento do uso desse tipo de material; a menos que o professor compre o seu próprio equipamento. $\mathrm{O}$ uso dos celulares na escola, normalmente, é proibido, nem todas as escolas dispõe de redes wifi. Diante disso, é possível que o licenciando, quando formado, possa vir a ter momentos de insegurança quando for também alvo de observação.

No fragmento a seguir é descrita a cena de quando a licencianda iniciou a observação na escola:

Fragmento 5 RETM $_{4}$

\section{Observação ao professor:}

Percebemos que tanto a professora quanto os alunos não estão familiarizados com um estagiário dentro da sala.

\section{Regência}




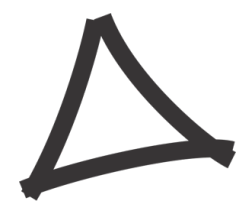

\section{Revista Triângulo}

www.seer.uftm.edu.br/revistaeletronica

(...) Com relação à professora, percebemos certo desconforto, ela se posicionou a frente da sala para fazer anotações sobre a regência, tal atitude gerou certo desconforto e apreensão, fazendo com que me sentisse coagida, não me sentindo a vontade (...).

Pela descrição acima, é possível observar que, na ocasião, a professora parece não ter se sentido confortável com a presença dela na sala. E ela também não se sentiu confortável quando a professora fez observação de sua regência. Eis um primeiro indício de conflito. Temse, portanto, um jogo de imagens formulado. A imagem que a licencianda pensa que a professora supervisora tem dela $\left(\mathrm{I}_{\mathrm{A}} \mathrm{B}\right)$ : "ela se posicionou a frente da sala para fazer anotações sobre a regência, tal atitude gerou certo desconforto e apreensão, fazendo com que me sentisse coagida, não me sentindo a vontade". Assim, na formulação de Pêcheux, poderia ser representada com a pergunta: Quem é ele (professor) para eu (licencianda) the falar assim? Ou melhor, quem é a professora para que eu licencianda me comporte assim? Levando em consideração a posição e o lugar, as condições de produção desse discurso, o professor se posiciona assim, dado o papel social que representa, de alguém que está a frente de uma sala de aula, tem experiência em relação à aluna que por sua vez, se sente coagida por ser avaliada por alguém cuja posição é proeminente. A conclusão é que na visão da licencianda a imagem que ela tem da professora, é de alguém que se sente insegura com sua presença. Tal atitude, numa análise discursiva, abre possibilidades para uma gama de implícitos, como o fato da professora ser iniciante na profissão e não estar acostumada com a presença de estagiários. $\mathrm{O}$ fato da própria insegurança da licencianda levá-la a antecipar a ideia que a anotação da professora é referente à sua regência: "ela se posicionou a frente da sala para fazer anotações sobre a regência,: "tal atitude gerou certo desconforto e apreensão, fazendo com que me sentisse coagida, não me sentindo a vontade".

Diante disso e concluindo, a escrita do licenciando aponta traços importantes do papel do professor que não podem ser ignorados. Ainda que haja falhas no processo de ensino aprendizagem é preciso considerar que o professor e o aluno são as partes mais importantes nesse processo, e o professor não é responsável sozinho pelo insucesso do ensino.

\section{CONSIDERAÇÕES FINAIS}

Os relatórios de estágio são documentos de suma importância para conhecimento do 


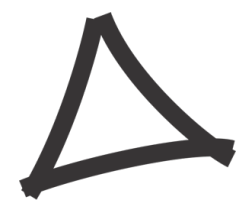

Revista Triângulo

www.seer.uftm.edu.br/revistaeletronica

papel do professor em sala de aula, e a escrita enquanto objeto de estudo torna-se uma ferramenta indispensável para investigação das práticas podendo revelar dados que muitas vezes não são evidentes. Buscou-se neste trabalho refletir como a imagem do professor se delineia para o licenciando, professor em formação, de modo a saber, como ele se posiciona ante a um discurso recorrente e contraproducente do trabalho que o professor tem desenvolvido na sala de aula.

Vale ressaltar que o propósito não é defender uma posição oposta à percepção do licenciando acerca do professor, mas compreender como e porque ainda há regularidade de discurso de queixa ao trabalho deste profissional. Nas análises foi possível perceber semelhanças nas duas realidades apresentadas no que diz respeito ao discurso que põe em evidência o trabalho realizado pelo licenciando, de modo que sobressaia ao trabalho do professor supervisor de estágio.

Observou-se também que imagem do professor supervisor para o professor em formação está muito aquém do esperado. Ele ainda é visto como alguém despreparado, cansado, sem criatividade nas duas realidades apresentadas. A descrição aponta para atuação do licenciando como aquele que irá "salvaguardar" o conhecimento não adquirido pelo aluno, dada às tantas fragilidades no ensino do professor. E esse tipo de afirmação tende a reforçar o julgamento e qualificá-lo como inábil para o trabalho na sala de aula

\section{REFERÊNCIAS}

BARZOTTO, Valdir Heitor. Leitura, escrita e relação com o conhecimento. Campinas, SP: Mercado de Letras, 2016. 182 p.

CARDOSO, Silvia Helena Barbi. Discurso e ensino. São Paulo: Ed. Autentica, 2017.

FAIRCHILD, T. A escrita sobre as práticas de ensino em licenciaturas do Brasil, da Costa Rica e de Honduras: registro, análise e produção de conhecimento. [s. n] Pará: Chamada universal MCTI/CNPQ no 14/2014, 2010.

FERNANDEZ, Alicia. A mulher escondida na professora. Disponível em: http://br.groups.yahoo.com/group/digital_source/acesso em: 16/09/2017 


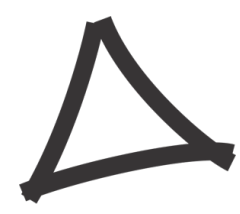

Revista Triângulo

www.seer.uftm.edu.br/revistaeletronica

GATTI, Bernadete Angelina; BARRETTO, Elba Siqueira de Sá; ANDRÉ, Marli Eliza Dalmazo de Afonso. Contexto contemporâneo, cultura, educação e políticas voltadas aos docentes. Ministério da Educação. Políticas docentes no Brasil: um estado da arte. Brasília: UNESCO, 2011, p. 23-30. Disponível em: http://unesdoc.unesco.org/images/0021/002121/212183por.pdf>

PÊCHEUX \& FUCHS (1975). A propósito da Análise Automática do Discurso. In: GADET \& HAK (org.). Por uma análise automática do discurso. Campinas: Ed. Unicamp, 2014, p.91-106

POSSENTI, Sírio. Teoria do discurso: um caso de múltiplas rupturas. In: Mussalim e Bentes (Orgs.) Introdução à linguística: domínios e fronteiras. São Paulo: Ed. Cortez, 2004 